\section{Category}

Polymer-

Supported

Synthesis

\section{Key Words}

\section{cooperative} phenomena heterogeneous catalysis mesoporous materials organic-inorganic hybrid composites silicon

S. HUN, H.-T. CHEN, J. W. WIENCH, M. PRUSKI, V. S.-Y. LIN* (IOWA STATE UNIVERSITY, USA) Cooperative Catalysis by General Acid and Base Bifunctionalized Mesoporous Silica Nanospheres Angew. Chem. Int. Ed. 2005, 44, 1826-1830.

\title{
Cooperative Catalysis by General Acid and Base Bifunctionalized Mesoporous Silica Nanospheres
}<smiles>CC(=O)C=Cc1ccc([N+](=O)[O-])cc1</smiles>

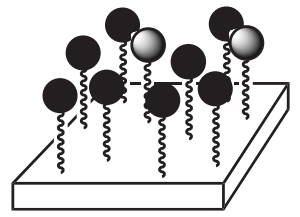

2/8 AEP/UDP-MSN<smiles>CO[Si](C)(C)CCCNCCNCCN</smiles><smiles>C[Si](C)(C)CCCNC(N)=O</smiles>

Significance: Bifunctinalized mesoporous silica nanospheres (MSNs) having a general acid, the ureidopropyl group (UDP), and a general base, 3-[2-(2-aminoethylamino)ethylamino]propyl group (AEP), were synthesized. The AEP/UDP-MSNs catalyzed the carbonyl activation reactions, aldol reaction, Henry reaction, and cyanosilylation with high TONs up to 22.6, 125.0, and 276.1, respectively.
Comment: Recently, a new synthetic method to functionalize mesoporous silica with multiple organic groups was reported from the author's group, by which the loading of functional groups, particle size, and shape of the mesoporous silicas could be controlled (for example, see: S. Huh, J. W. Wiench, J.-C. Yoo, M. Pruski, V. S.-Y. Lin Chem. Mater. 2003, 15, 4247-4256). The authors discussed that the AEP and the UDP activate both the nucleophile and the electrophile at the same time, cooperatively. 